\title{
The Endocannabinoid System Affects Myocardial Glucose Metabolism in the DOCA-Salt Model of Hypertension
}

\author{
Agnieszka Polak $^{\mathrm{a}}$ Ewa Harasim-Symbora Barbara Malinowska $^{\mathrm{b}}$ Irena Kasackac \\ Alicja Lewandowskac Adrian Chabowski \\ ${ }^{a}$ Department of Physiology, Medical University of Bialystok, Bialystok, bepartment of Experimental \\ Physiology and Pathophysiology, Medical University of Bialystok, Bialystok, 'Department of Histology \\ and Cytophysiology, Medical University of Bialystok, Bialystok, Poland
}

\section{Key Words}

Doca • Endocannabinoids • GLUT • Hypertension • Insulin • URB597

\begin{abstract}
Background/Aims: Recent interest in the use of cannabinoids as therapeutic agents has revealed the involvement of the endogenous cannabinoid system (ECS) in the regulation of the cardiovascular system in hypertension. Abnormalities in glucose metabolism and insulin action are commonly detected in hypertensive animals. Thus, potential antihypertensive drugs should be investigated with respect to modulation of glucose homeostasis. Therefore, the aim of the present study was to evaluate the effects of the ECS activation after chronic fatty acid amide hydrolase inhibitor (URB597) administration on plasma glucose and insulin concentrations as well as parameters of myocardial glucose metabolism in the deoxycorticosterone acetate (DOCA)-salt hypertensive rats, an animal model of secondary hypertension. Methods: Hypertension was induced by DOCA $(25 \mathrm{mg} / \mathrm{kg})$ injections and addition of $1 \% \mathrm{NaCl}$ in the drinking water for six weeks. Chronic activation of the ECS was performed by URB597 $(1 \mathrm{mg} / \mathrm{kg})$ injections for two weeks. We examined fasting plasma levels of insulin (ELISA), glucose and intramyocardial glycogen (colorimetric method). Expressions of glucose transporters (GLUT1, 4) and selected proteins engaged in GLUT translocation as well as glucose metabolism were determined using Western blotting. Results: Hypertension induced hypoinsulinemia with concomitant lack of significant changes in glycemia, reduced intramyocardial glycogen content and increased pyruvate dehydrogenase (PDH) expression in the cardiac muscle. Importantly, chronic URB597 administration in the hypertensive rats increased insulin concentration, elevated plasmalemmal GLUT1 and GLUT4 expression and concomitantly improved myocardial glycogen storage. Conclusion: Chronic administration of fatty acid amide hydrolase (FAAH) inhibitor has potential protective properties on myocardial glucose metabolism in hypertension.




\section{Cellular Physiology Cell Physiol Biochem 2018;46:727-739 and Biochemistry Published online: April 05, $2018 \quad$\begin{tabular}{l|l} 
DOI: 10.1159/000488730 & $\begin{array}{l}\text { C } 2018 \text { The Author(s). Published by S. Karger AG, Basel } \\
\text { www.karger.com/cpb }\end{array}$
\end{tabular} Polak et al.: Effect of URB597 on Myocardial Glucose Metabolism}

\section{Introduction}

Long chain fatty acids (LCFA) and glucose are the major energy substrates of the myocardium, which supply nearly $80 \%$ and $20 \%$ of ATP, respectively. The uptake of both substrates is controlled mostly by plasma membrane protein transporters [1]. It is known that glucose transport is regulated by glucose transporters 1 and 4 (GLUT1 and GLUT4) in the cardiomyocytes [2]. GLUT1 is an insulin-independent glucose transporter responsible for basal glucose transport $[3,4]$. In contrast, GLUT4 is translocated to the cell surface in response to insulin [1], ischemia or cardiac overload [5]. Importantly, total expression and translocation of glucose transporters from an intracellular depot to the plasma membrane adjusts glucose influx to the current myocardial energy demands [5].

Hypertension is one of the most common diseases of civilization. Interestingly, glucose intolerance and insulin resistance have been recently reported for patients with hypertension [6]. Moreover, there is a growing body of evidence that indicates a shift in myocardial energy substrate preference from LCFA to glucose in hypertension $[7,8]$. This suggests that high blood pressure is a relevant factor affecting not only whole-body, but also myocardial energy metabolism.

There is a large variety of drugs lowering blood pressure, however, current strategies have not been successful in the treatment of different types of hypertension. Recently, there has been renewed interest in the use of cannabinoids for therapeutic purposes and their effects on the endogenous cannabinoid system (ECS). This system is composed of arachidonate-based ligands, such as anandamide (AEA), which exert their effects by interacting with metabotropic cannabinoid receptors 1 and $2\left(\mathrm{CB}_{1}\right.$ and $\left.\mathrm{CB}_{2}\right)$ [9]. It should be mentioned that fatty acid amide hydrolase (FAAH) is an enzyme, which is responsible for AEA degradation and, therefore, determines endocannabinoids activity in the tissues [10]. Interestingly, studies have shown that both, acute and chronic pharmacological FAAH inhibition by (30-(aminocarbonyl)[1, 10-biphenyl]-3-yl)-cyclohexylcarbamate (URB597) administration normalized elevated blood pressure $[11,12]$. Since the ECS controls energy homeostasis [13] we wanted to determine whether decreased FAAH activity would have an impact on cardiac metabolism.

Therefore, the purpose of this study was to examine the effects of the ECS activation, after chronic inhibition of FAAH (URB597 treatment) in the hypertensive rats, on myocardial glucose metabolism. In our research we conducted experiments on the deoxycorticosterone acetate (DOCA)-salt rats, a commonly used animal model of secondary hypertension [14-17]. We have assessed parameters of myocardial glucose metabolism, including total expression and subcellular redistribution of glucose transporters, expression of key enzymes involved in glycolysis metabolic pathway and Krebs cycle, proteins engaged in GLUT translocation as well as intramyocardial glycogen content. Moreover, plasma levels of insulin and glucose were measured in this study along with insulin sensitivity indexes.

\section{Materials and Methods}

Source of chemicals

DOCA, dimethyl sulfoxide (DMSO) and N,N-dimethylformamide (DMF) were purchased from SigmaAldrich (Steinheim, Germany). 30-(aminocarbonyl)[1, 10-biphenyl]-3-yl)-cyclohexylcarbamate (URB597), Glucose Assay Kit (ab65333) and Glycogen Colorimetric Assay Kit II (Catalog \#K648-100) were obtained from Cayman Chemical Company (Ann Arbour, MI, USA), Abcam (Cambridge, UK) and BioVision Inc. (Milpitas, CA, USA), respectively. Mercodia Rat Insulin ELISA (10-1250-01) were received from Mercodia AB (Uppsala, Sweden). Antibodies were obtained from following sources: anti-AMPK (\#2532), anti-phospho-AMPK (\#2535S), anti-AKT (\#4691L), anti-phospho-AKT (\#9271S), anti-p44/42 MAPK (anti-MAPK3/1) (\#9102), anti-phospho-p44/42 MAPK (anti-phospho-MAPK3/1) (\#4377S) - Cell Signalling Technology (Danvers, MA, USA), anti-GAPDH (sc-32233), anti-GLUT1 (sc-7903), anti-GLUT4 (sc-53566) and anti-Na ${ }^{+} / \mathrm{K}^{+}-$pump (sc-30110) - Santa Cruz Biotechnology (Santa Cruz, CA, USA), anti-CS (ab129095), anti-PDH (ab110333) 


\section{Cellular Physiology Cell Physiol Biochem 2018;46:727-739 \begin{tabular}{l|l} 
and Biochemistry Published online: Apri| 05, 2018 & $\begin{array}{l}\text { D) } 2018 \text { The Author(s). Published by S. Karger AG, Basel } \\
\text { www.karger.com/cpb }\end{array}$
\end{tabular}}

Polak et al.: Effect of URB597 on Myocardial Glucose Metabolism

- Abcam (Cambridge, UK). All appropriate secondary antibodies conjugated with horseradish peroxidase used in this study (donkey anti-goat - sc-2020; mouse anti-rabbit - sc-2357; goat anti mouse - sc-2005) were purchased from Santa Cruz Biotechnology (Santa Cruz, CA, USA) and an enhanced chemiluminescence substrate was obtained from ThermoFisher Scientific (Waltham, MA, USA).

Animal care and diet

Male Wistar rats (Center for Experimental Medicine, Medical University of Bialystok, Poland) of 6-7 week of age, weighing $170-200 \mathrm{~g}$, were used in this model. The animals were housed at $22 \pm 1^{\circ} \mathrm{C}$ with $12: 12$ hours light-dark cycle and had free access to water and a standard pelleted chow (Labofeed B, Animal Feed Manufacturer "Morawski", Kcynia, Poland). Our experimental protocol was approved by the Ethical Committee for Animal Experiments at the Medical University of Bialystok.

\section{Experimental model of DOCA-salt hypertension}

The rats were randomly divided into four groups of 6 rats each:

(I) CONTROL: normotensive, control rats;

(II) URB597: normotensive rats treated with URB597;

(III)DOCA-salt: hypertensive rats;

(IV)DOCA-salt + URB597: hypertensive rats treated with URB597.

Right uninephrectomy was performed on all rats. The animals were anaesthetized with intraperitoneal injection of pentobarbitone sodium ( $300 \mu \mathrm{mol} / \mathrm{kg}$ body weight). The kidney was visualized by a right lateral abdominal incision and right renal artery. Then, the ureter was ligated by silk thread and the right kidney was removed. After 7 days of recovery, rats were divided into two groups: normotensive and hypertensive. Rats from the normotensive group received subcutaneous injections of DOCA solvent - DMF (N,N-dimethylformamide) twice a week for six consecutive weeks and tap water to drink. Simultaneously, the hypertensive rats were given $1 \% \mathrm{NaCl}$ in the drinking water with concomitant injections of DOCA (25 $\mathrm{mg} / \mathrm{kg}$ [18-21] in $0.4 \mathrm{ml} / \mathrm{kg}$ DMF). After 4 weeks, half of the normotensive and half of the hypertensive animals were injected with URB597 $(1 \mathrm{mg} / \mathrm{ml} / \mathrm{kg})$ twice a day for the next 2 weeks [12, 22, 23]. At the same time the rest of rats received URB597 solvent - DMSO (1 ml/kg; Tween 80 and $0.9 \% \mathrm{NaCl}$ (1:2:7)). In some studies URB597 is used at a dose of $0.3 \mathrm{mg} / \mathrm{kg}$ [24], which may reduce endocannabinoid-induced effects [25]. Moreover, it was demonstrated that chronic URB597 injections at a dose of $1 \mathrm{mg} / \mathrm{kg}$ enhanced AEA levels and exhibited anti-inflammatory properties [26] as well as anti-nociceptive and anxiolytic-like activity [27]. It should be also mentioned that the short half-life span of URB597 limits its chronic use [24]. Therefore, URB597 therapy is more effective (e.g. in arthritis severity) when the dose frequency is increased from one to two times a day [28].

Moreover, hemodynamic parameters, body and heart weights as well as cardiomyocytes dimension were monitored throughout the study and included in our previous article [29]. Briefly, induction of DOCAsalt hypertension caused a significant increase in mean blood pressure (MBP, $+42.9 \%$ vs control group) value.

\section{Collection of samples}

Twelve hours after the last dose of URB597 or its solvent, rats were sacrificed under pentobarbitone sodium anaesthesia. Then, samples of the left ventricle were excised and immediately frozen in liquid nitrogen. Moreover, blood samples were collected in heparinized tubes, centrifuged and the plasma was separated. All samples were stored at $-80^{\circ} \mathrm{C}$ for further analysis.

\section{Plasma measurements}

Fasting plasma glucose (FPG) concentration was determined with the use of Glucose Assay Kit (Abcam, Cambridge, UK), as specified by the manufacturer. Briefly, glucose was measured by incubating samples with appropriate reaction mix for 30 minutes at $37^{\circ} \mathrm{C}$. During incubation glucose was oxidized generating a colourful product. The absorbance was measured at $570 \mathrm{~nm}$. Glucose concentration was expressed in nanomoles per microlilter of sample. Moreover, fasting plasma insulin (FPI) concentration was determined using Rat Insulin ELISA Kit (Mercodia AB, Uppsala, Sweden). Insulin concentration was measured at 450nm and expressed in microunits per milliliter. Intra- and inter-assay coefficients of variations were less than $3.7 \%$ and less than 5.8\%, respectively. The values were calculated on the basis of a standard curve constructed for 


\section{Cellular Physiology Cell Physiol Biochem 2018;46:727-739 \begin{tabular}{cc|c} 
DOI: 10.1159/000488730 & O 2018 The Author(s). Published by S. Karger AG, Basel \\
www.karger.com/cpb
\end{tabular}}

Polak et al.: Effect of URB597 on Myocardial Glucose Metabolism

each assay. At the end of each measurement the intensity of coloured products was measured in a hybrid multi-mode microplate reader (Synergy H1 ${ }^{\mathrm{TM}}$, BioTek Instruments, Winooski, VT, USA).

We also evaluated insulin sensitivity indexes (validated in Wistar rats [30]): the homeostasis model assessment of insulin resistance (HOMA-IR $=(\mathrm{FPG} \times \mathrm{FPI}) / 2,430)$, the quantitative insulin sensitivity check index (QUICKI $=1 /[\log (\mathrm{FPG})+\log (\mathrm{FPI})])$ and the fasting glucose/insulin ratio $(\mathrm{FGIR}=\mathrm{FPG} / \mathrm{FPI})$, where FPG was expressed in milligrams per deciliter and FPI in microunits per milliliter in each equation.

\section{Intramyocardial glycogen analysis}

The glycogen content was determined using a colorimetric method (Glycogen Colorimetric Assay Kit II, BioVision Inc., Milpitas, CA, USA) following manufacturer's protocol. In brief, samples of the left ventricle were homogenized in glycogen hydrolysis buffer and centrifuged. Collected supernatants were diluted 20 times prior to adding development enzyme mix. After incubation, absorbance of glycogen products was measured at $450 \mathrm{~nm}$ using a hybrid multi-mode microplate reader (Synergy $\mathrm{H}^{\mathrm{TM}}{ }^{\mathrm{T}}$, BioTek Instruments, Winooski, VT, USA). Determinations of unknown concentrations of samples were based on standard curve. Glycogen concentration was expressed in micrograms per microliter of sample.

\section{Subcellular fractionation of cardiac myocytes}

Subcellular fractionation of the cardiac myocytes was performed to examine changes in the expression of GLUT1 and GLUT4 at the level of plasma membranes (PM) and low density microsomes (LDM). Isolation of PM and LDM was carried out according to Fuller et al. method [31], with modifications described in details by Kalinowska et al. [32]. The purity of isolated fractions was evaluated by Western blotting using appropriate markers, i.e. ATPase sodium/potassium pump $\left(\mathrm{Na}^{+} / \mathrm{K}^{+}\right.$pump) for plasma membranes and sarcoplasmic/endoplasmic reticulum calcium ATPase for endosomal membranes (SERCA). Plasmalemmal and intramyocellular protein expression was normalized to $\mathrm{Na}^{+} / \mathrm{K}^{+}$pump or SERCA expression, respectively.

\section{Western blotting}

For detecting total, plasmalemmal and intramyocellular protein expression Western blotting procedure was used, as it was described [33]. Briefly, bichinchoninic acid (BCA) method with bovine serum albumin (BSA) as a standard was applied for protein concentration determination. Samples were subjected to $10 \%$ sodium dodecyl sulphate (SDS) polyacrylamide gel electrophoresis and wet transfer. Next, the membranes were blocked in Tris Buffer Saline Tween20 (TBST; $20 \mathrm{mM}$ Tris, $150 \mathrm{mM} \mathrm{NaCl}, 0.1 \%$ Tween20) containing $5 \%(\mathrm{wt} / \mathrm{vol})$ non-fat dry milk or BSA. Thereafter, the membranes were incubated with primary antibodies overnight, diluted in TBST: citrate synthase (CS; 1:1000), protein kinase B (AKT; 1:1000), phosphorylated AKT (phospho-AKT; 1:1000), AMP-activated protein kinase (AMPK; 1:1000), phosphorylated AMPK (phospho-AMPK; 1:1000), glyceraldehyde 3-phosphate dehydrogenase (GAPDH; 1:500), GLUT1 (1:500), GLUT4 (1:500), mitogen-activated protein kinase (p44/42 MAPK; MAPK3/1; 1:1000), phosphorylated MAPK (phospho-p44/42 MAPK; phospho-MAPK3/1; 1:1000) and pyruvate dehydrogenase (PDH; 1:1000). Then, the membranes were washed and incubated with appropriate secondary antibodies conjugated with horseradish peroxidase and diluted (1:3000) in TBST. The examined proteins were visualized using an enhanced chemiluminescence substrate and obtained signals were quantified by densitometry (ChemiDoc visualization system, Bio Rad, Warsaw, Poland). Routine Ponceau S staining was used to confirm equal protein loading in each lane $(30 \mu \mathrm{g})$. Protein expression was standardized to GAPDH expression. Experimental groups were expressed relative to the control group, which was set as $100 \%$.

\section{Immunohistochemical analysis}

In the immunohistochemical (IHC) study, the EnVision method was used according to Herman and Elfont [34]. Before commencing IHC staining for GLUT1 and GLUT4 recommended antigen retrieval was performed using Target Retrieval Solution $\mathrm{pH}=9.0$ (S2367; Dako, Dennmark). Thereafter tissues were blocked in Peroxidase Blocking Reagent (S 2001 Dako Denmark A/S, Produktionsvej 42, DK-2600 Glostrup) for 10 minutes at room temperature. Sections were incubated with primary antibodies i.e. GLUT1 and GLUT4 for 1 hour in room temperature. HRP polymer KIT was used as the secondary antibody for 30 minutes followed by colorimetric detection using chromogen DAB. Sections were counterstained with hematoxilin and dehydrated with pure ethanol and xylene to prepare for mounting. The obtained results of immunohistochemical staining were submitted for evaluation on an Olympus BX41 microscope with an 
Olympus DP12 camera under a magnification of 200x (20x lens and 10x eyepiece). Morphometric analysis of images was performed using NIS-Elements Advanced Research software of Nikon. The intensity of the immunohistochemical reaction was measured using a 0 to 256 grey scale level in ten randomly selected sites of each rat's heart, in which white or bright pixels received a value of 0 and a completely black pixels were given a value of 256 .

\section{Statistical analysis}

All presented data are expressed as mean values \pm SD and based on six independent rats. Statistical differences between groups were tested with two-way analyses of variance (ANOVA) and appropriate post hoc tests using GraphPad Prism 5 (GraphPad Software Inc., La Jolla, CA, USA). Statistical significance level was set at $\mathrm{P}<0.05$.

\section{Results}

Effect of prolonged activation of the ECS on plasma glucose and insulin concentrations and insulin sensitivity indexes in the DOCA-salt hypertension

Induction of DOCA-salt hypertension significantly reduced plasma insulin concentration and HOMA-IR in rats $(-68.7 \%$ and $-68.2 \%, \mathrm{P}<0.05$, Fig. $1 \mathrm{~b}$ and Table 1 , respectively) and concomitantly increased QUICKI as well as FGIR indexes $(+14.9 \%$ and $+300 \%, \mathrm{P}<0.05$, Tab. 1 , respectively) compared to the normotensive group. Interestingly, FAAH inhibition in the DOCA-salt rats resulted in significantly elevated HOMA-IR $(+40.7 \%, \mathrm{P}<0.05$, Tab. 1$)$ as well as reduced QUICKI and FGIR ( $-6 \%$ and $-46.9 \%, \mathrm{P}<0.05$, Tab. 1, respectively) in comparison with the hypertensive group. However, all examined parameters in the hypertensive rats after chronic URB597 treatment were still substantially different from those observed in both, the normotensive rats alone and treated with URB597 (plasma insulin $-50.5 \%$ and $-37 \%$; HOMAIR $-57.3 \%$ and $-44.5 \%$; QUICKI $+8 \%$ and $+5.9 \%$; FGIR $+59.9 \%$ and $+23 \%$; $\mathrm{P}<0.05$, Fig. $1 \mathrm{~b}$ and Table 1, respectively).

Table 1. Indexes of insulin sensitivity after prolonged activation of the ECS in the DOCA-salt hypertension. The data are expressed as the mean $\pm \mathrm{SD}, \mathrm{n}=6$ in each group. ${ }^{\mathrm{a}} \mathrm{P}<0.05$ significant difference: control vs examined group; ${ }^{\mathrm{b}} \mathrm{P}<0.05$ significant difference: URB597 vs DOCA+URB597; ${ }^{\mathrm{P}}<0.05$ significant difference: DOCA vs DOCA+URB597

\begin{tabular}{lcccc}
\hline & CONTROL & DOCA & URB597 & DOCA+URB597 \\
& & & & \\
\hline HOMA-IR & $1.78 \pm 0.76$ & $0.54 \pm 0.26^{\mathrm{a}}$ & $1.37 \pm 0.71$ & $0.76 \pm 0.25^{\mathrm{a}, \mathrm{b}, \mathrm{c}}$ \\
& & & & \\
QUICKI & $0.264 \pm 0.015$ & $0.303 \pm 0.018^{\mathrm{a}}$ & $0.269 \pm 0.016$ & $0.285 \pm 0.014^{\mathrm{a}, \mathrm{b}, \mathrm{c}}$ \\
& & & & \\
FGIR $\left(\mathrm{mg} / 10^{-4} \mathrm{U}\right)$ & $1.37 \pm 0.66$ & $4.13 \pm 1.74^{\mathrm{a}}$ & $1.78 \pm 0.85$ & $2.19 \pm 0.55^{\mathrm{a}, \mathrm{b}, \mathrm{c}}$
\end{tabular}

Fig. 1. Plasma concentrations of glucose (a) and insulin (b) and intramyocardial glycogen content (c) after prolonged activation of the ECS in the DOCA-salt hypertension. The data are expressed as the mean $\pm S D, n=6$ in each group. ${ }^{\mathrm{a}} \mathrm{P}<0.05$ significant difference: control vs examined group; ${ }^{\mathrm{b}}<0.05$ significant difference: URB597 vs DOCA+URB597; ${ }^{\mathrm{P}}<0.05$ significant difference: DOCA vs DOCA+URB597.

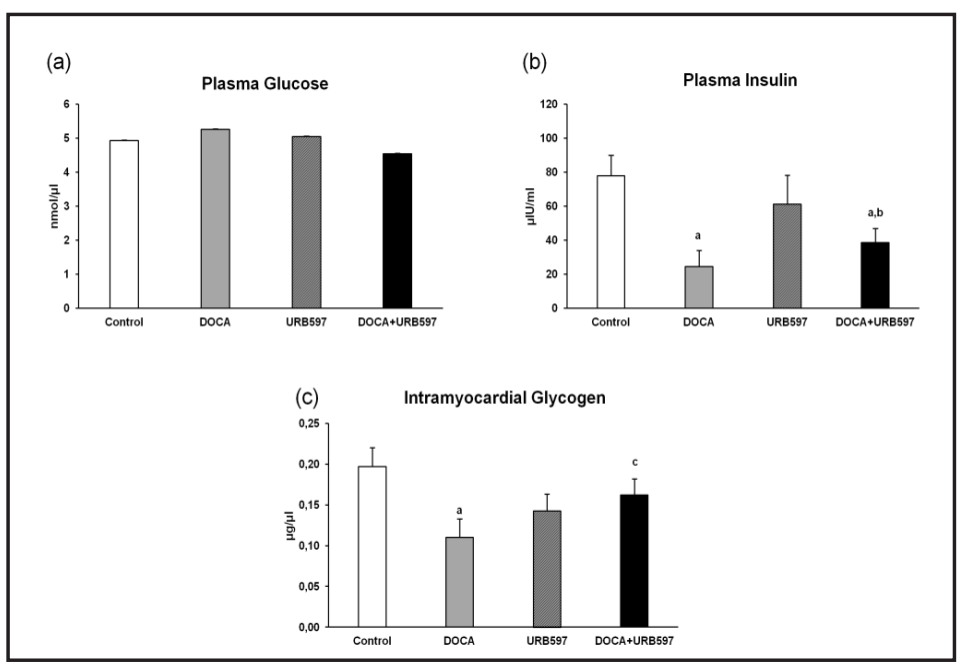


Fig. 2. The total expression of GLUT1 (a) and GLUT 4 (c) in the left ventricle after prolonged activation of the ECS in the DOCAsalt hypertension. Expression of GLUT1 (b) and GLUT4 (d) in plasma membranes (PM) and low density microsomes (LDM) in the left ventricle after prolonged activation of the ECS in the DOCA-salt hypertension. The data are expressed as a percentage of the control group (mean $\pm \mathrm{SD}$ ), $\mathrm{n}=6$ in each group. ${ }^{\mathrm{P}}<0.05$ significant difference: control vs examined group.
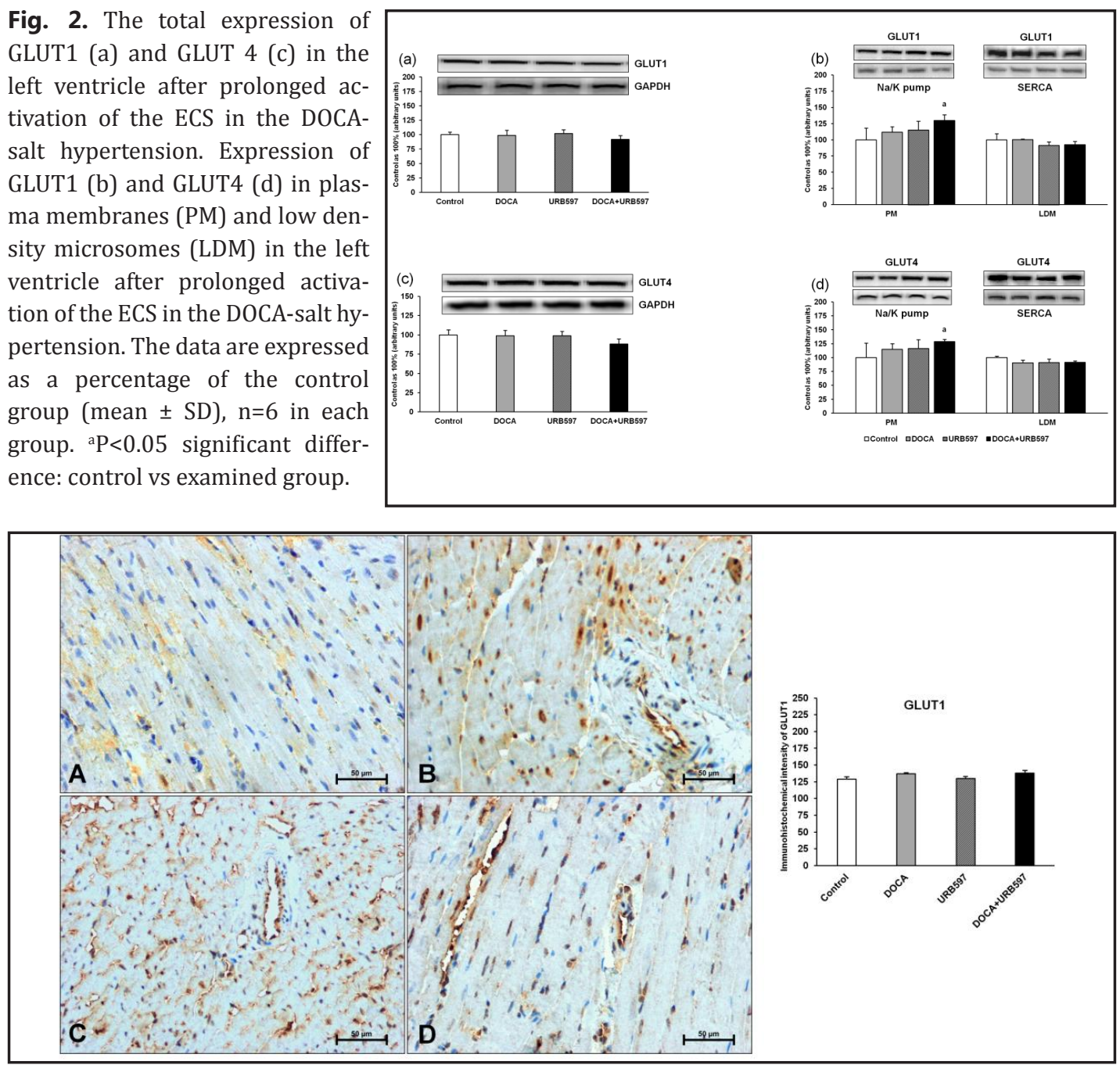

Fig. 3. Representative photomicrographs of the rats' cardiac muscle tissue after GLUT1 immunohistochemical staining: (A) CONTROL, (B) DOCA, (C) URB597 and (D) DOCA+URB597. Scale bars equal 50 $\mu \mathrm{m}$. The bar graph presents the intensity of GLUT1 immunohistochemical staining in the left ventricle after prolonged activation of the ECS in the DOCA-salt hypertension. The data are expressed as mean $\pm S D, n=6$ in each group.

Effect of prolonged activation of the ECS on the myocardial glycogen content in the DOCAsalt hypertension

We recorded a marked decrease in the content of glycogen in the left ventricle in the DOCA-salt group in comparison with the normotensive group $(-44.1 \%, \mathrm{P}<0.05$, Fig. 1 c). Interestingly, chronic URB597 administration significantly increased intramyocardial glycogen level in the DOCA-salt rats compared to the hypertensive group alone $(+47.3 \%$, $\mathrm{P}<0.05$, Fig. 1c). Additionally, a trend toward decrease in the cardiac glycogen stores was observed in the normotensive rats after chronic FAAH inhibition compared to the normotensive group (-27.6\%, P=0.19, Fig. 1c).

Effect of prolonged activation of the ECS on the myocardial total and subcellular expression of glucose transporters in the DOCA-salt hypertension

We observed that the total expression of both glucose transporters remained unchanged in all examined groups and only chronic FAAH inhibition significantly elevated plasmalemmal expression of GLUT1 as well as GLUT4 $(+29.2 \%$ and $+28.5 \%, \mathrm{P}<0.05$, Fig. 2 b,d, respectively; vs. normotensive group) in the hypertensive rats. 


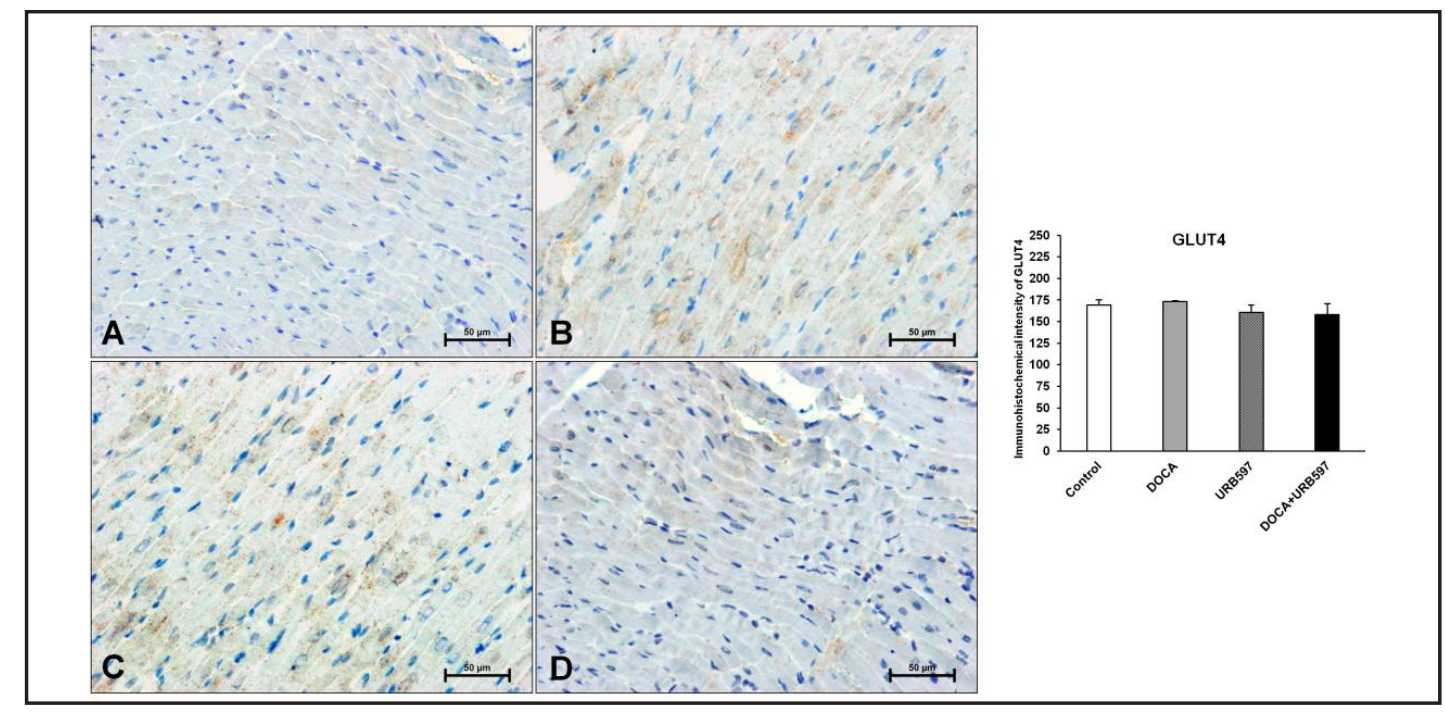

Fig. 4. Representative photomicrographs of the rats' cardiac muscle tissue after GLUT4 immunohistochemical staining: (A) CONTROL, (B) DOCA, (C) URB597 and (D) DOCA+URB597. Scale bars equal 50 $\mu$ m. The bar graph presents the intensity of GLUT4 immunohistochemical staining in the left ventricle after prolonged activation of the ECS in the DOCA-salt hypertension. The data are expressed as mean $\pm S D, n=6$ in each group.

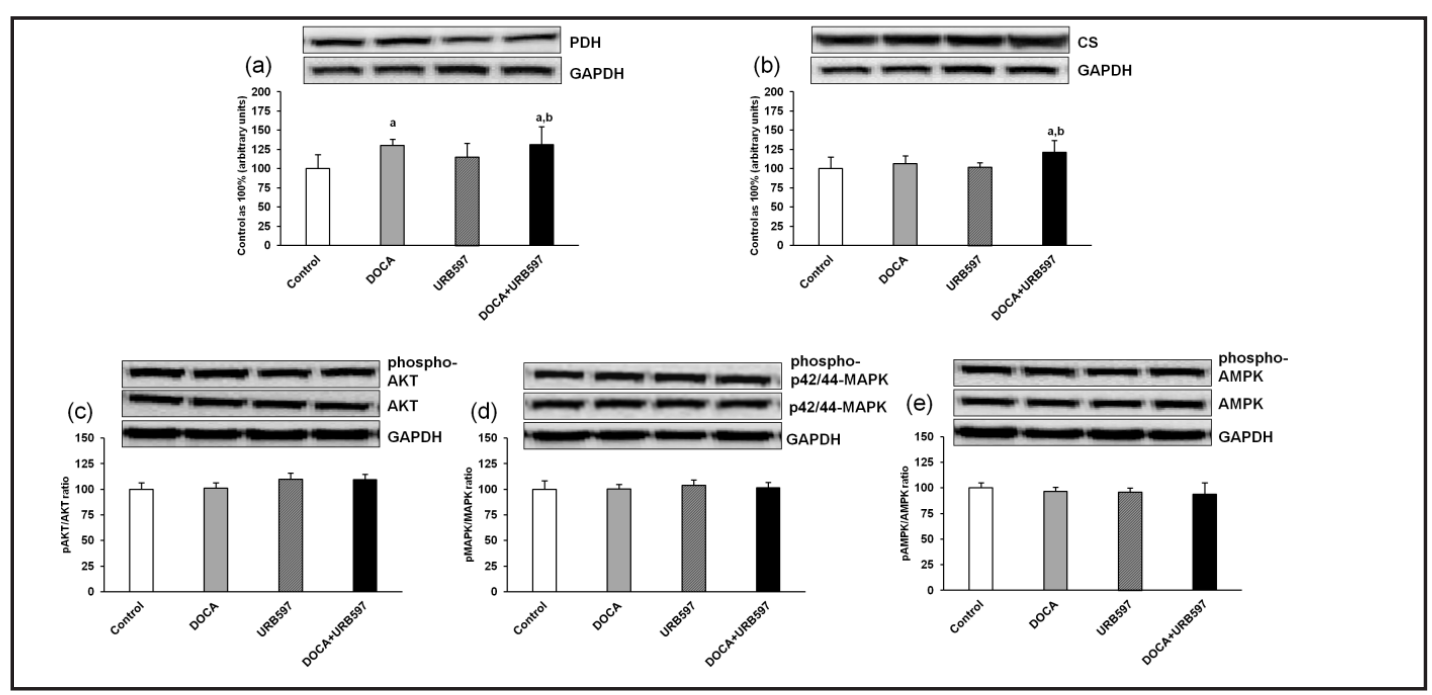

Fig. 5. The total expression of PDH (a), CS (b) and phospho-AKT/AKT (c), phospho-p44/42-MAPK/p44/42MAPK (phospho-MAPK3/1/MAPK3/1; phospho-ERK1/2/ERK1/2) ratio (d) and phospho-AMPK/AMPK ratio (e) in the left ventricle after prolonged activation of the ECS in the DOCA-salt hypertension. The data are expressed as a percentage of the control group (mean $\pm \mathrm{SD}$ ), $\mathrm{n}=6$ in each group. ${ }^{\mathrm{P}}<0.05$ significant difference: control vs examined group; ${ }^{b} \mathrm{P}<0.05$ significant difference: URB597 vs DOCA+URB597.

Effect of prolonged activation of the ECS on the myocardial total expression of PDH, CS, phospho-AKT, AKT, phospho-p44/42 MAPK, p44/42 MAPK, phospho-AMPK, and AMPK in the DOCA-salt hypertension

Induction of hypertension in the DOCA-salt rats resulted in a significant increase in the myocardial PDH expression in comparison with the normotensive control group $(+30.1 \%, \mathrm{P}<0.05$, Fig. 5a). Nonetheless, PDH expression in the hypertensive group after the ECS activation was still elevated in comparison with the normotensive group alone as well as treated with URB597 $(+31.1 \%$ and $+14.1 \%$, P $<0.05$, Fig. $5 a$, respectively). Moreover,

\section{KARGER}




\section{Cellular Physiology Cell Physiol Biochem 2018;46:727-739 \begin{tabular}{ll|l} 
DOI: 10.1159/000488730 & O 2018 The Author(s). Published by S. Karger AG, Basel \\
www.karger.com/cpb
\end{tabular} \\ Polak et al.: Effect of URB597 on Myocardial Glucose Metabolism}

there was a considerable increase in the myocardial CS expression in the DOCA-salt rats after chronic FAAH inhibition in comparison with both the URB597 untreated and treated normotensive groups $(+21.2 \%$ and $+18.9 \%$, $\mathrm{P}<0.05$, Fig. $5 \mathrm{~b}$, respectively).

\section{Discussion}

\section{DOCA-salt-induced hypertension.}

In the present study we examined the effect of DOCA-salt induction of hypertension on the myocardial glucose metabolism. It is well known that insulin has a significant impact on the metabolism of insulin-sensitive tissues by promoting the absorption of glucose from the blood into the cells, including cardiomyocytes. In our study the DOCA-salt rats had substantially reduced plasma insulin concentration, which was in line with previous findings [20, 35, 36]. Ndisang et al. revealed presence of severe inflammation and fibrosis in the pancreatic tissue in the DOCA-salt rats, which might be the cause of decreased insulinproducing capability of $\beta$-cells [36]. Interestingly, as in others [20,36], also in our study depressed circulating insulin level was not coupled with hyperglycemia in the DOCA-salt rats, thus glucose availability for the heart remained unchanged. Therefore, we investigated whether DOCA-salt hypertension had an influence on insulin sensitivity indexes. The DOCAsalt rats had significantly lower values of HOMA-IR and simultaneously greater QUICKI as well as FGIR indexes, which may indicate that increased tissue insulin sensitivity was compensating reduced plasma insulin level. Consequently, it is possible that glucose influx into the cells could be stable.

Moreover, it is well established that the rate of glucose metabolism depends on glucose transport related to the number of special carrier proteins (in the heart especially GLUT1 and GLUT4). In our study the total and subcellular expression of both transporters as well as phosphorylation of proteins engaged in glucose transporters translocation (AKT, p44/42MAPK, AMPK) were unchanged in the DOCA-salt heart homogenates, which may suggest that the transport rate was not altered. In addition, lack of differences in the total GLUT4 expression in the DOCA-salt rat hearts was consistent with the results obtained by Atkins et al. [37]. It is likely that enhanced needs for energy production in the pressure-overloaded heart [38] was not followed by alterations in the total glucose transporters expression as well as their intracellular translocation. However, increased workload resulted in decreased intramyocardial glycogen content, as it was confirmed also by Coprean et al. [39]. Likewise, this phenomenon was demonstrated in the cardiomyocytes of DOCA-salt rats in the presence of glucose in the incubation medium [39]. These data suggest that glycogen is an important carbohydrate source for the heart in hypertension. On the other hand, low insulin level in the DOCA-salt hypertension observed in our study can explain intensified myocardial glycogen depletion [40]. It is likely that the above mentioned alterations might reflect a switch in the hypertensive state towards increased glucose utilization in the cardiomyocytes [41]. It is not surprising because $10 \%$ more ATP is generated from glycolysis than fatty acid oxidation per mole of oxygen [42]. Thus, glucose is more effective source of energy when heart is subjected to higher work (such as in hypertension), especially in hypertrophied heart [43], which was also present in our model and described previously [29]. Moreover, elevated myocardial expression of PDH in our study might reveal that in hypertension, pyruvate was mainly converted into acetyl-Co-A linking the glycolysis pathway to the Krebs cycle, which takes place only in aerobic conditions. Therefore, it indicates on enhanced myocardial glycolysis rate in the DOCA-salt rats.

\section{Effects of URB597 chronic administration in the normotensive hearts}

Prolonged activation of the ECS in our study had no effect on either glycaemia or insulin sensitivity indexes, although a trend for decreased plasma insulin concentration in the normotensive rats after chronic FAAH inhibition was observed. Others also noted that URB597 did not change fasting glucose concentration in the normotensive WKY rats [44]. In contrary, 
the latest reports indicate that URB597 may affect plasma glucose level in the WKY rat strain but only non-fasting stage $[23,45]$. Interestingly, recent studies provide contradictory data regarding the effects of the ECS stimulation on insulin secretion from $\beta$ cells and plasma insulin concentration [46-50]. Accordingly, Anderson et al. [51] revealed that inhibition of FAAH with URB597, as in our study, did not alter basal as well as glucose-induced insulin release from isolated islets of Langerhans. While Rivera et al. [23] reported that WKY rats had lower basal insulin concentration in plasma. Therefore, the exact mechanism of the ECS action (FAAH inhibition) on insulin secretion still remains unknown.

Our data indicate that chronic URB597 application in the normotensive rats did not affect cardiac metabolism, since all examined parameters of myocardial glucose homeostasis were unchanged compared to the normotensive control group (Fig. 3-5).

\section{Effects of URB597 chronic administration in the DOCA-salt hearts}

In our study prolonged activation of the ECS by URB597 treatment partially restored plasma insulin level in the DOCA-salt hypertensive rats, which was not accompanied by a change in glycemia. This observation is especially interesting since some antihypertensive agents exhibit adverse effects on glucose homeostasis inducing e.g. hyperglycaemia, insulin resistance or diabetes mellitus, which might be linked with future cardiovascular disorders [52].

It is well established that insulin promotes both translocation of glucose transporters [53] and glycogen synthesis in the heart. Therefore, it is possible that restored insulin concentration was, at least to some extent, responsible for increased presence of glucose transporters (GLUT4) at the plasma membranes. Probably, this insulin-dependent translocation may be the consequence of increased AKT activity since we observed a trend toward elevated phosphorylation of this kinase after chronic FAAH inhibition. The latest reports indicate that ECS activation by URB597 application may activate AKT signalling in the central nervous system $[54,55]$. Although there is no data on URB597 action on AKT pathway in the myocardium, the results of other studies revealed that activation of the ECS by other compounds induced an increase in AKT phosphorylation in the heart [56-58].

When hypertension was combined with the ECS activation we observed a statistically significant increase in plasmalemmal glucose transporters expression. This fact demonstrates that the ECS probably takes part in the regulation of heart glucose metabolism in hypertension. Since GLUTs translocation is usually associated with increased glucose influx into cells it is possible that FAAH inhibition improved cardiomyocytes glucose supply [59]. As a result myocardial glycogen content was restored compared to the DOCA-salt group alone. We may speculate that restoring glycogen levels in the DOCA-salt rats heart may have a cardioprotective role since others have shown that greater myocardial glycogen content protects the heart against hypoxia [60] and lowers the incidence of complications in patients after bypass surgery [61]. It was also shown that glycogen depletion occurs in several heart disorders [62-64] and, additionally, the absence of myocardial glycogen is associated with abnormal cardiac development in a mouse model of muscle glycogen synthase knockout [65]. Furthermore, as in the hypertensive group alone, after prolonged ECS activation intensified myocardial glycolysis was noticed (elevated PDH expression) in the DOCA salt rats. However, it does not appear to be a result of the ECS activation, since myocardial PDH expression remained unchanged in spite of URB597 application in the hypertensive rats. Interestingly, expression of routinely used metabolic marker of aerobic capacity and mitochondrial function, CS [66, 67], was increased, which indicates that ECS activation in the hypertensive rats may support mitochondrial energy generation in the cardiac muscle.

\section{Conclusion}

The present study describes the effects of induced hypertension together with ECS activation on myocardial glucose metabolism. We found that hypertensive status in the 


\section{Cellular Physiology Cell Physiol Biochem 2018;46:727-739 \begin{tabular}{l|l} 
and Biochemistry Published 10.1159/000488730 & $\begin{array}{l}\text { (c) } 2018 \text { The Author(s). Published by S. Karger AG, Basel } \\
\text { www.karger.com/cpb }\end{array}$
\end{tabular} \\ Polak et al.: Effect of URB597 on Myocardial Glucose Metabolism}

DOCA-salt rats caused intramyocardial glycogen depletion. Interestingly, this intensified consumption of intracellular carbohydrate stores was not compensated by increase in glucose transport. Chronic FAAH inhibition in the hypertensive rats restored myocardial glycogen content, presumably through improved circulating insulin concentration, which was accompanied by elevated expression of glucose transporters at the plasma membranes. Our findings indicate that URB597 treatment may improve cardiac glucose metabolism in the DOCA-salt rats.

\section{Acknowledgements}

This work was supported by the National Centre in Poland (grant number NCN 2012/05/B/NZ7/03102) and Medical University of Bialystok (grant numbers: N/ST/ MN/17/003/1118 and N/ST/ZB/17/005/1118).

\section{Disclosure Statement}

No conflicts of interests exists.

\section{References}

1 Ware B, Bevier M, Nishijima Y, Rogers S, Carnes CA, Lacombe VA: Chronic heart failure selectively induces regional heterogeneity of insulin-responsive glucose transporters. Am J Physiol Regul Integr Comp Physiol 2011;301:1300-1306.

2 Zorzano A, Sevilla L, Camps M, Becker C, Meyer J, Kammermeier H, Muñoz P, Gumà A, Testar X, Palacín M, Blasi J, Fischer Y: Regulation of glucose transport, and glucose transporters expression and trafficking in the heart: studies in cardiac myocytes. Am J Cardiol 1997;80:65A-76A.

-3 Pessin JE, Bell GI: Mammalian facilitative glucose transporter family: structure and molecular regulation. Annu Rev Physiol 1992;54:911-930.

4 Santalucía T, Camps M, Castelló A, Muñoz P, Nuel A, Testar X, Palacin M, Zorzano A: Developmental regulation of GLUT-1 (erythroid/Hep G2) and GLUT-4 (muscle/fat) glucose transporter expression in rat heart, skeletal muscle, and brown adipose tissue. Endocrinology 1992;130:837-846.

5 Wheeler TJ, Fell RD, Hauck MA: Translocation of two glucose transporters in heart: effects of rotenone, uncouplers, workload, palmitate, insulin and anoxia. Biochim Biophys Acta 1994;1196:191-200.

6 Gouveia LM, Paccola GM, Torquato MT, Menezes FO, Piccinato CE, Foss MC: Peripheral glucose metabolism in patients with essential hypertension. Horm Metab Res 2000;32:35-39.

7 Dodd MS, Ball DR, Schroeder MA, Le Page LM, Atherton HJ, Heather LC, Seymour AM, Ashrafian H, Watkins H, Clarke K, Tyler DJ: In vivo alterations in cardiac metabolism and function in the spontaneously hypertensive rat heart. Cardiovasc Res 2012;95:69-76.

-8 Hajri T, Ibrahimi A, Coburn CT, Knapp FF, Kurtz T, Pravenec M, Abumrad NA: Defective fatty acid uptake in the spontaneously hypertensive rat is a primary determinant of altered glucose metabolism, hyperinsulinemia, and myocardial hypertrophy. J Biol Chem 2001;276:23661-23666.

-9 Howlett AC: Cannabinoid receptor signaling. Handb Exp Pharmacol 2005:53-79.

10 Pacher P, Bátkai S, Osei-Hyiaman D, Offertáler L, Liu J, Harvey-White J, Brassai A, Járai Z, Cravatt BF, Kunos G: Hemodynamic profile, responsiveness to anandamide, and baroreflex sensitivity of mice lacking fatty acid amide hydrolase. Am J Physiol Heart Circ Physiol 2005;289:533-541.

11 Bátkai S, Pacher P, Osei-Hyiaman D, Radaeva S, Liu J, Harvey-White J, Offertáler L, Mackie K, Rudd MA, Bukoski RD, Kunos G: Endocannabinoids acting at cannabinoid-1 receptors regulate cardiovascular function in hypertension. Circulation 2004;110:1996-2002. 


\section{Cellular Physiology Cell Physiol Biochem 2018;46:727-739 \begin{tabular}{c|c|c|} 
DOI: 10.1159/000488730 & C 2018 The Author(s). Published by S. Karger AG, Basel \\
www.karger.com/cpb
\end{tabular}

-12 Toczek M, Baranowska-Kuczko M, Grzęda E, Pędzińska-Betiuk A, Weresa J, Malinowska B: Age-specific influences of chronic administration of the fatty acid amide hydrolase inhibitor URB597 on cardiovascular parameters and organ hypertrophy in DOCA-salt hypertensive rats. Pharmacological Reports 2016;68:363369.

13 Silvestri C, Di Marzo V: The endocannabinoid system in energy homeostasis and the etiopathology of metabolic disorders. Cell Metab 2013;17:475-490.

14 Rodríguez JA, Lopez JM, Biglieri EG: DOCA test for aldosteronism: its usefulness and implications. Hypertension 1981;3:102-106.

15 Iyer A, Chan V, Brown L: The DOCA-Salt Hypertensive Rat as a Model of Cardiovascular Oxidative and Inflammatory Stress. Curr Cardiol Rev 2010;6:291-297.

16 Lee LK, Kim MY, Kim JH, Lee JU, Park BS, Yang SM, Jeon HJ, Lee WD, Noh JW, Kwak TY, Lee TH, Kim JY, Kim HY, Hwang BY, Kim B, Kim J: A review of deoxycorticosterone acetate-salt hypertension and its relevance for cardiovascular physiotherapy research. J Phys Ther Sci 2015;27:303-307.

17 Schenk J, McNeill JH: The pathogenesis of DOCA-salt hypertension. J Pharmacol Toxicol Methods 1992;27:161-170.

18 Loch D, Hoey A, Morisseau C, Hammock BO, Brown L: Prevention of hypertension in DOCA-salt rats by an inhibitor of soluble epoxide hydrolase. Cell Biochem Biophys 2007;47:87-98.

19 Prahalathan P, Saravanakumar M, Raja B: The flavonoid morin restores blood pressure and lipid metabolism in DOCA-salt hypertensive rats. Redox Rep 2012;17:167-175.

20 Dai S, McNeill JH: Myocardial performance of STZ-diabetic DOCA-hypertensive rats. Am J Physiol 1992;263:1798-1805.

-21 Pedzinska-Betiuk A, Weresa J, Toczek M, Baranowska-Kuczko M, Kasacka I, Harasim-Symbor E, Malinowska B: Chronic inhibition of fatty acid amide hydrolase by URB597 produces differential effects on cardiac performance in normotensive and hypertensive rats. Br J Pharmacol 2017;174:2114-2129.

22 Clapper JR, Duranti A, Tontini A, Mor M, Tarzia G, Piomelli D: The fatty-acid amide hydrolase inhibitor URB597 does not affect triacylglycerol hydrolysis in rat tissues. Pharmacol Res 2006;54:341-344.

23 Rivera P, Bindila L, Pastor A, Pérez-Martín M, Pavón FJ, Serrano A, de la Torre R, Lutz B, Rodríguez de Fonseca F, Suárez J: Pharmacological blockade of the fatty acid amide hydrolase (FAAH) alters neural proliferation, apoptosis and gliosis in the rat hippocampus, hypothalamus and striatum in a negative energy context. Front Cell Neurosci 2015;9:98.

24 Piomelli D, Tarzia G, Duranti A, Tontini A, Mor M, Compton TR, Dasse O, Monaghan EP, Parrott JA, Putman D: Pharmacological profile of the selective FAAH inhibitor KDS-4103 (URB597). CNS Drug Rev 2006;12:2138.

-25 Okine BN, Norris LM, Woodhams S, Burston J, Patel A, Alexander SP, Barrett DA, Kendall DA, Bennett AJ, Chapman V: Lack of effect of chronic pre-treatment with the FAAH inhibitor URB597 on inflammatory pain behaviour: evidence for plastic changes in the endocannabinoid system. Br J Pharmacol 2012;167:627-640.

-26 Murphy N, Cowley TR, Blau CW, Dempsey CN, Noonan J, Gowran A, Tanveer R, Olango WM, Finn DP, Campbell VA, Lynch MA: The fatty acid amide hydrolase inhibitor URB597 exerts anti-inflammatory effects in hippocampus of aged rats and restores an age-related deficit in long-term potentiation. J Neuroinflammation 2012;9:79.

27 Busquets-Garcia A, Puighermanal E, Pastor A, de la Torre R, Maldonado R, Ozaita A: Differential role of anandamide and 2-arachidonoylglycerol in memory and anxiety-like responses. Biol Psychiatry 2011;70:479-486.

28 Kinsey SG, Naidu PS, Cravatt BF, Dudley DT, Lichtman AH: Fatty acid amide hydrolase blockade attenuates the development of collagen-induced arthritis and related thermal hyperalgesia in mice. Pharmacol Biochem Behav 2011;99:718-725.

-29 Polak A, Harasim-Symbor E, Malinowska B, Kasacka I, Pędzińska-Betiuk A, Weresa J, Chabowski A: The effects of chronic FAAH inhibition on myocardial lipid metabolism in normotensive and DOCA-salt hypertensive rats. Life Sci 2017;183:1-10.

-30 Cacho J, Sevillano J, de Castro J, Herrera E, Ramos MP: Validation of simple indexes to assess insulin sensitivity during pregnancy in Wistar and Sprague-Dawley rats. Am J Physiol Endocrinol Metab 2008;295:1269-1276. 


\section{Cellular Physiology Cell Physiol Biochem 2018;46:727-739 \begin{tabular}{c|c} 
DOI: 10.1159/000488730 & Ond Biochemistry 2018 The Author(s). Published by S. Karger AG, Basel \\
wwww.karger.com/cpb
\end{tabular}

-31 Fuller W, Eaton P, Medina RA, Bell J, Shattock MJ: Differential centrifugation separates cardiac sarcolemmal and endosomal membranes from Langendorff-perfused rat hearts. Anal Biochem 2001;293:216-223.

-32 Kalinowska A, Górski J, Harasim E, Harasiuk D, Bonen A, Chabowski A: Differential effects of chronic, in vivo, PPAR's stimulation on the myocardial subcellular redistribution of FAT/CD36 and FABPpm. FEBS Lett 2009;583:2527-2534.

-33 Harasim E, Stępek T, Konstantynowicz-Nowicka K, Baranowski M, Górski J, Chabowski A: Myocardial Lipid Profiling During Time Course of High Fat Diet and its Relationship to the Expression of Fatty Acid Transporters. Cell Physiol Biochem 2015;37:1147-1158.

-34 Herman GE, Elfont EA: The taming of immunohistochemistry: the new era of quality control. Biotech Histochem 1991;66:194-199.

35 Dai S, Fraser H, McNeill JH: Effects of deoxycorticosterone acetate on glucose metabolism in nondiabetic and streptozotocin-diabetic rats. Can J Physiol Pharmacol 1992;70:1468-1472.

-36 Ndisang JF, Jadhav A: The heme oxygenase system attenuates pancreatic lesions and improves insulin sensitivity and glucose metabolism in deoxycorticosterone acetate hypertension. Am J Physiol Regul Integr Comp Physiol 2010;298:211-223.

-37 Atkins KB, Johns D, Watts S, Clinton Webb R, Brosius FC: Decreased vascular glucose transporter expression and glucose uptake in DOCA-salt hypertension. J Hypertens 2001;19:1581-1587.

-38 Fortuño MA, Ravassa S, Fortuño A, Zalba G, Díez J: Cardiomyocyte apoptotic cell death in arterial hypertension: mechanisms and potential management. Hypertension 2001;38:1406-1412.

-39 Coprean D, Roşioru C, Toma V, Tofan L: Heart metabolic modifications induced by nifedipine treatment in normo- and hypertensive Wistar rats. Rom J Physiol 1993;30:109-113.

-40 Chandramouli C, Varma U, Stevens EM, Xiao RP, Stapleton DI, Mellor KM, Delbridge LM: Myocardial glycogen dynamics: new perspectives on disease mechanisms. Clin Exp Pharmacol Physiol 2015;42:415425.

41 Randle PJ, Garland PB, Hales CN, Newsholme EA: The glucose fatty-acid cycle. Its role in insulin sensitivity and the metabolic disturbances of diabetes mellitus. Lancet 1963;1:785-789.

42 Stanley WC, Chandler MP: Energy metabolism in the normal and failing heart: potential for therapeutic interventions. Heart Fail Rev 2002;7:115-130.

43 Allard MF, Schönekess BO, Henning SL, English DR, Lopaschuk GD: Contribution of oxidative metabolism and glycolysis to ATP production in hypertrophied hearts. Am J Physiol 1994;267:742-750.

44 Hasanein P, Parviz M, Keshavarz M, Roohbakhsh A: URB597, an inhibitor of fatty acid amide hydrolase, reduces hyperalgesia in diabetic rats. Can J Physiol Pharmacol 2009;87:432-439.

-45 Godlewski G, Alapafuja SO, Bátkai S, Nikas SP, Cinar R, Offertáler L, Osei-Hyiaman D, Liu J, Mukhopadhyay B, Harvey-White J, Tam J, Pacak K, Blankman JL, Cravatt BF, Makriyannis A, Kunos G: Inhibitor of fatty acid amide hydrolase normalizes cardiovascular function in hypertension without adverse metabolic effects. Chem Biol 2010;17:1256-1266.

-46 Nakata M, Yada T: Cannabinoids inhibit insulin secretion and cytosolic Ca2+ oscillation in islet beta-cells via CB1 receptors. Regul Pept 2008;145:49-53.

-47 Juan-Picó P, Fuentes E, Bermúdez-Silva FJ, Javier Díaz-Molina F, Ripoll C, Rodríguez de Fonseca F, Nadal A: Cannabinoid receptors regulate $\mathrm{Ca}(2+)$ signals and insulin secretion in pancreatic beta-cell. Cell Calcium 2006;39:155-162.

48 Li C, Bowe JE, Jones PM, Persaud SJ: Expression and function of cannabinoid receptors in mouse islets. Islets 2010;2:293-302.

49 Vilches-Flores A, Delgado-Buenrostro NL, Navarrete-Vázquez G, Villalobos-Molina R: CB1 cannabinoid receptor expression is regulated by glucose and feeding in rat pancreatic islets. Regul Pept 2010;163:8187.

50 Bermúdez-Silva FJ, Suárez J, Baixeras E, Cobo N, Bautista D, Cuesta-Muñoz AL, Fuentes E, Juan-Pico P, Castro MJ, Milman G, Mechoulam R, Nadal A, Rodríguez de Fonseca F: Presence of functional cannabinoid receptors in human endocrine pancreas. Diabetologia 2008;51:476-487.

51 Anderson RL, Randall MD, Chan SL: The complex effects of cannabinoids on insulin secretion from rat isolated islets of Langerhans. Eur J Pharmacol 2013;706:56-62.

-52 Blackburn DF, Wilson TW: Antihypertensive medications and blood sugar: theories and implications. Can J Cardiol 2006;22:229-233. 


\section{Cellular Physiology Cell Physiol Biochem 2018;46:727-739 \begin{tabular}{l|l} 
DOI: 10.1159/000488730 & $\begin{array}{l}\text { O 2018 The Author(s). Published by S. Karger AG, Basel } \\
\text { www.karger.com/cpb }\end{array}$
\end{tabular} \\ Polak et al.: Effect of URB597 on Myocardial Glucose Metabolism}

53 Egert S, Nguyen N, Schwaiger M: Myocardial glucose transporter GLUT1: translocation induced by insulin and ischemia. J Mol Cell Cardiol 1999;31:1337-1344.

54 Su SH, Wang YQ Wu YF, Wang DP, Lin Q, Hai J: Cannabinoid receptor agonist WIN55, 212-2 and fatty acid amide hydrolase inhibitor URB597 may protect against cognitive impairment in rats of chronic cerebral hypoperfusion via PI3K/AKT signaling. Behav Brain Res 2016;313:334-344.

55 Vilela LR, Gobira PH, Viana TG, Medeiros DC, Ferreira-Vieira TH, Doria JG, Rodrigues F, Aguiar DC, Pereira GS, Massessini AR, Ribeiro FM, de Oliveira AC, Moraes MF, Moreira FA: Enhancement of endocannabinoid signaling protects against cocaine-induced neurotoxicity. Toxicol Appl Pharmacol 2015;286:178-187.

56 Li Q Wang F, Zhang YM, Zhou JJ, Zhang Y: Activation of cannabinoid type 2 receptor by JWH133 protects heart against ischemia/reperfusion-induced apoptosis. Cell Physiol Biochem 2013;31:693-702.

57 Li Q Shi M, Li B: Anandamide enhances expression of heat shock protein 72 to protect against ischemiareperfusion injury in rat heart. J Physiol Sci 2013;63:47-53.

58 Matouk AI, Taye A, El-Moselhy MA, Heeba GH, Abdel-Rahman AA: The Effect of Chronic Activation of the Novel Endocannabinoid Receptor GPR18 on Myocardial Function and Blood Pressure in Conscious Rats. J Cardiovasc Pharmacol 2017;69:23-33.

59 Shao D, Tian R: Glucose Transporters in Cardiac Metabolism and Hypertrophy. Compr Physiol 2015;6:331351.

60 Scheuer J, Stezoski SW: Protective role of increased myocardial glycogen stores in cardiac anoxia in the rat. Circ Res 1970;27:835-849.

-61 Iyengar SR, Charrette EJ, Iyengar CK, Wasan S: Myocardial glycogen in prevention of perioperative ischemic injury of the heart: a preliminary report. Can J Surg 1976;19:246-251.

62 King LM, Opie LH: Glucose delivery is a major determinant of glucose utilisation in the ischemic myocardium with a residual coronary flow. Cardiovasc Res 1998;39:381-392.

63 Vigoda A, Mamedova LK, Shneyvays V, Katz A, Shainberg A: Glycogen metabolism in rat heart muscle cultures after hypoxia. Mol Cell Biochem 2003;254:311-318.

64 Kolwicz SC, Tian R: Glucose metabolism and cardiac hypertrophy. Cardiovasc Res 2011;90:194-201.

65 Pederson BA, Chen H, Schroeder JM, Shou W, DePaoli-Roach AA, Roach PJ: Abnormal cardiac development in the absence of heart glycogen. Mol Cell Biol 2004;24:7179-7187.

-66 Garnier A, Fortin D, Deloménie C, Momken I, Veksler V, Ventura-Clapier R: Depressed mitochondrial transcription factors and oxidative capacity in rat failing cardiac and skeletal muscles. J Physiol 2003;551:491-501.

67 Larsen S, Nielsen J, Hansen CN, Nielsen LB, Wibrand F, Stride N, Schroder HD, Boushel R, Helge JW, Dela F, Hey-Mogensen M: Biomarkers of mitochondrial content in skeletal muscle of healthy young human subjects. J Physiol 2012;590:3349-3360. 